\title{
Desain dan Implementasi Robot Heksapoda dengan Misi Pemadaman Api
}

\author{
Asep Najmurrokhman, Kusnandar, Bambang HSR Wibowo, Nizwar Alwi Rafanca \\ Jurusan Teknik Elektro, Fakultas Teknik \\ Universitas Jenderal Achmad Yani \\ Jl. Terusan Jend. Sudirman PO Box 148 Cimahi 40533 \\ asepnajmu@yahoo.com
}

\begin{abstract}
Abstrak-Makalah ini memaparkan tentang desain dan implementasi robot heksapoda yang bergerak dalam suatu ruang dengan misi memadamkan api. Sumber api diletakkan dalam ruang tertentu. Untuk mencapai ruang tersebut, robot harus berjalan menyusuri lorong dengan lebar tertentu dan dibatasi oleh dinding. Robot harus bergerak tanpa menabrak dinding pembatas ruang. Untuk merealisasikan sistem tersebut, robot heksapoda dilengkapi dengan tiga buah sensor, yaitu sensor jarak, sensor garis, dan sensor api. Sensor jarak berupa sensor ultrasonik tipe HCSR04 berfungsi memberikan informasi jarak antara robot dengan dinding sehingga robot terhindar dari tabrakan dengan dinding. Sensor garis berupa sensor LDR digunakan untuk mendeteksi garis penanda ruang sumber api. Sementara itu, sensor api berupa sensor flame 5 channel berfungsi mendeteksi keberadaan api yang harus dipadamkan oleh robot. Hasil eksperimen menunjukkan robot heksapoda yang dirancang dapat berjalan menyusuri ruang tanpa menabrak dinding dan menemukan sumber api, kemudian api tersebut dipadamkan oleh kipas yang berputar setelah diberi tegangan input oleh mikrokontroler.
\end{abstract}

Kata kunci- mikrokontroler Arduinomega2560; robot heksapoda; sensor api; sensor garis; sensor ultrasonik

\section{Pendahuluan}

Penelitian terkait robot berjalan (walking robot) merupakan salahsatu penelitian bidang robotika yang paling menantang. Beberapa peneliti telah berusaha membangun robot berjalan selama beberapa tahun terakhir. Secara umum, robot berjalan terbagi menjadi dua kelompok, yaitu robot berkaki dan robot beroda. Robot berkaki dipandang lebih unggul dibandingkan dengan robot beroda saat berjalan di atas permukaan yang relatif kasar karena robot berkaki tidak memerlukan kontak yang kontinyu dengan permukaan jalannya [1]. Robot berkaki yang dikembangkan selama ini biasanya memiliki dua kaki, empat kaki, dan enam kaki. Robot dengan dua kaki disebut dengan robot humanoid, karena bentuk robotnya mengikuti bentuk manusia. Sementara itu, robot berkaki empat dan berkaki enam umumnya disebut robot animaloid, karena bentuknya mengadopsi bentuk binatang. Robot berkaki empat mengambil bentuk anjing, kuda, atau cheetah, sedangkan robot berkaki enam memanipulasi bentuk laba-laba. Robot berkaki empat disebut dengan quadruped robot, sedangkan robot berkaki enam disebut dengan robot heksapoda. Salahsatu bentuk robot berkaki empat yang dibangun mengikuti bentuk cheetah diberikan dalam Gambar 1.

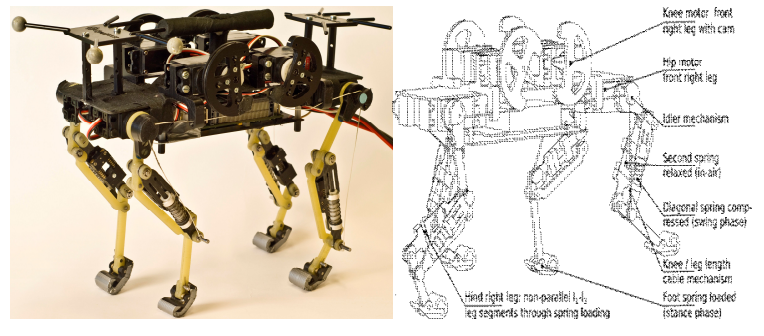

Gambar 1. Robot berkaki empat [2]

Dalam makalah ini, sebuah robot heksapoda dirancang dan direalisasikan agar memiliki kemampuan gerak menyusuri ruang berdinding dan memiliki misi untuk mencari sumber api kemudian memadamkannya. Selama bergerak, robot tidak boleh menabrak dinding yang ada dalam ruangan tersebut. Menurut Ding \& Yang dalam [1], robot yang dirancang dengan kaki lebih dari enam tidak berpengaruh kepada peningkatan kecepatan. Penelitian terkait robot heksapoda di antaranya menyangkut tentang penghindaran dari halangan dalam medan yang tidak dikenal [3,4], desain kendali hibrid [5,6], kendali getaran dan penjejakan presisi [7,8], dan penggunaan teknik pemrosesan citra [4,9]. Chai et al. dalam [3] mengusulkan dan memvalidasi kerangka kerja dalam teknik penghindaran dari halangan suatu robot heksapoda tertentu dalam tiga tahap. Yu \& Huang dalam [4] menggunakan teknik pemrosesan citra agar dapat diperoleh penghindaran halangan lebih efektif. Pemrosesan citra ini juga digunakan oleh Fischer et al. dalam [9] untuk menghasilkan pergerakan sebuah robot heksapoda yang baik dalam permukaan yang kasar. Zhong et al. dalam [5] mendeskripsikan teknik kendali hibrid yang menggabungkan teknik PID nonlinier, kendali sliding mode, dan impedance control dalam desain robot heksapoda. Sementara itu, Zhao et al. dalam [6] menerapkan teknik kendali hibrid dalam robot heksapoda yang digunakan untuk membantu proses permesinan. Wang et al. dalam [7] membahas tentang kendali getaran yang dapat mengganggu efektivitas gerak robot heksapoda, sedangkan Li et al. dalam [8] mengadopsi metode fuzzy adaptif dalam kendali getaran tersebut. 
Robot heksapoda yang dirancang dan direalisasikan dalam penelitian ini menggunakan komponen mikrokontroler dan sensor-sensor yang diperlukan. Robot memiliki misi memadamkan api. Sumber api disimpan di suatu ruang tertentu yang harus dilacak oleh robot tersebut. Untuk mencapai ruang dimana sumber api diletakkan, robot berjalan menyusuri ruangruang dengan lebar tertentu dan dibatasi oleh dinding. Robot harus bergerak tanpa menabrak dinding pembatas ruang. Mekanisme gerak dan misi robot seperti itu diadopsi dalam kompetisi robot antar mahasiswa yang diselenggarakan oleh Kemenristekdikti. Bentuk lintasan dan ruang-ruang yang ditentukan dalam kompetisi tersebut diberikan dalam Gambar 2.

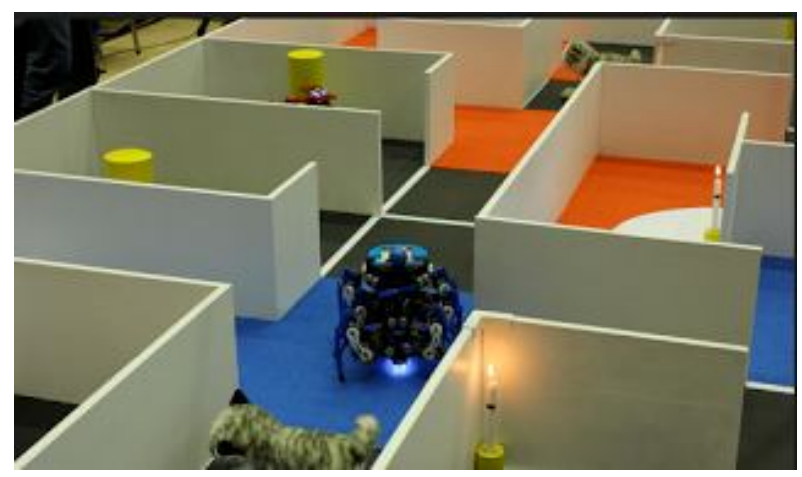

Gambar 2. Ruang bersekat dan berdinding dalam kompetisi robot antar mahasiswa [10]

\section{MetodE}

Diagram skematik robot heksapoda yang dirancang dan direalisasikan diberikan pada Gambar 3.

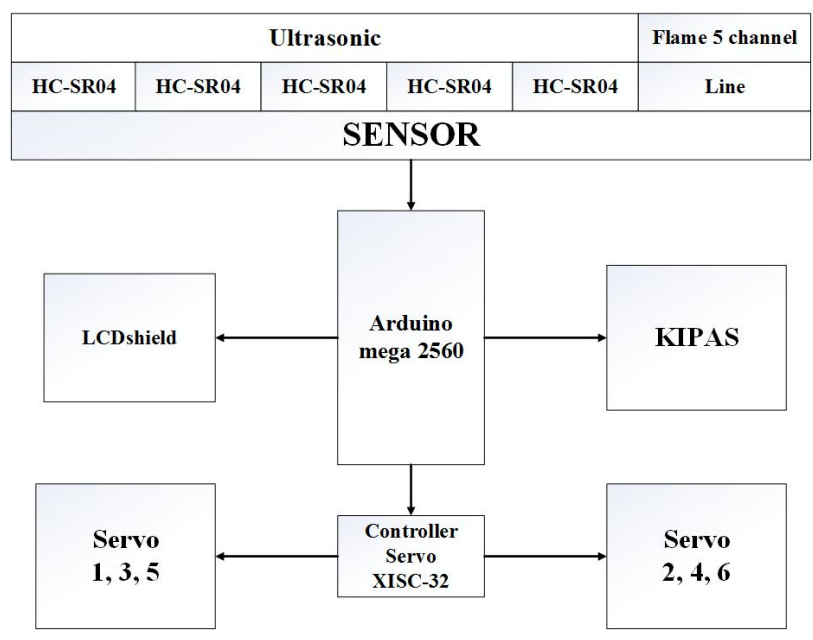

Gambar 3. Diagram skematik robot heksapoda

Komponen penyusun robot heksapoda terdiri atas mikrokontroler Arduinomega2560, sensor ultrasonik HCSR04, sensor garis LDR, sensor api Flame 5 channel, motor servo, kipas, dan penampil LCD. Mikrokontroler berfungsi sebagai pusat pengendali setiap proses dalam gerak robot, sedangkan sensor ultrasonik digunakan sebagai detektor jarak antara robot dengan dinding. Informasi jarak ini digunakan oleh robot agar tidak menabrak dinding selama geraknya.
Sementara itu, sensor api difungsikan untuk melacak keberadaan sumber api dan sensor garis digunakan untuk mengenali ruang tempat sumber api berada. Seluruh gerak kaki robot dilakukan melalui mekanisme pengiriman sinyal yang diatur oleh pengendali servo berdasarkan pengolahan data di mikrokontroler.

Robot heksapoda yang dirancang menggunakan lima buah sensor ultrasonik tipe HC-SR04 yang diletakkan pada sudut $0^{\circ} / 360^{\circ}, 45^{\circ}, 90^{\circ}, 135^{\circ}$, dan $180^{\circ}$. Gambar 4 memperlihatkan bentuk fisik sensor ultrasonik tersebut. Sensor tersebut umumnya digunakan dalam aplikasi pendeteksi jarak seperti pada [11]

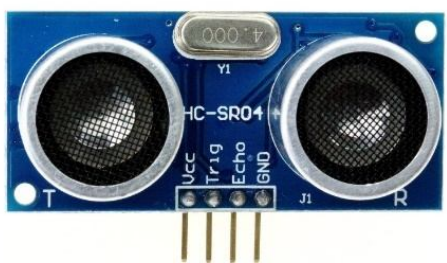

Gambar 4. Bentuk fisik sensor ultrasonik

Dengan empat buah pin pada sensor tersebut, yaitu Vcc, ground, echo, dan trigger, proses deteksi jarak dilakukan dengan pemberian sinyal dari pin trigger. Sinyal yang dipantulkan dan diterima oleh pin echo dicacah menjadi jarak sebenarnya dalam satuan $\mathrm{cm}$. Ilustrasi proses transmisi gelombang bunyi yang dikirimkan dan dipantulkan diberikan pada Gambar 5.

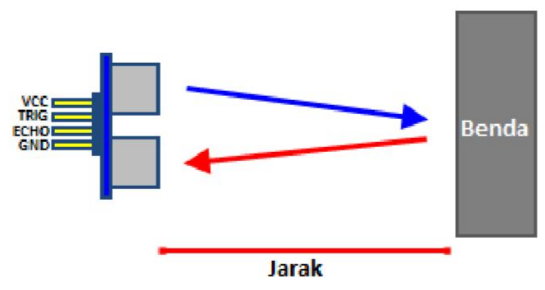

Gambar 5. Gelombang bunyi yang dipancarkan oleh sensor dan dipantulkan oleh benda

Sensor ultrasonik ini mampu mendeteksi jarak pengukuran hingga $400 \mathrm{~cm}$. Sensor tersebut mendeteksi objek dengan mengirimkan gelombang ultrasonik dengan frekuensi $40 \mathrm{KHz}$, yang kemudian menerima pantulan gelombangnya saat mendeteksi objek. Sensor HC-SR04 mengirimkan gelombang ultrasonik hanya jika ada pulsa high trigger dari mikrokontroler dengan durasi $10 \mu$ s untuk mengaktifkan sebuah sinyal 8 bit dengan frekuensi $40 \mathrm{KHz}$. Gelombang bunyi ini merambat di udara dengan laju sekitar $340 \mathrm{~m} / \mathrm{s}$ hingga mengenai objek. Jika sensor ini menerima pantulan maka pin echo akan berlogika high. Selanjutnya, perhitungan jarak diperoleh dengan mengalikan besar laju rambat gelombang ultrasonik dengan waktu tempuh gelombang dibagi dua. Diagram koneksi sensor ultrasonik dengan mikrokontroler diberikan pada Gambar 6. Kaki-kaki mikrokontroler yang dihubungkan dengan sensor ultrasonik ditentukan oleh pin 31, $33,35,37,39,41,43,45,47$, dan 49 . 


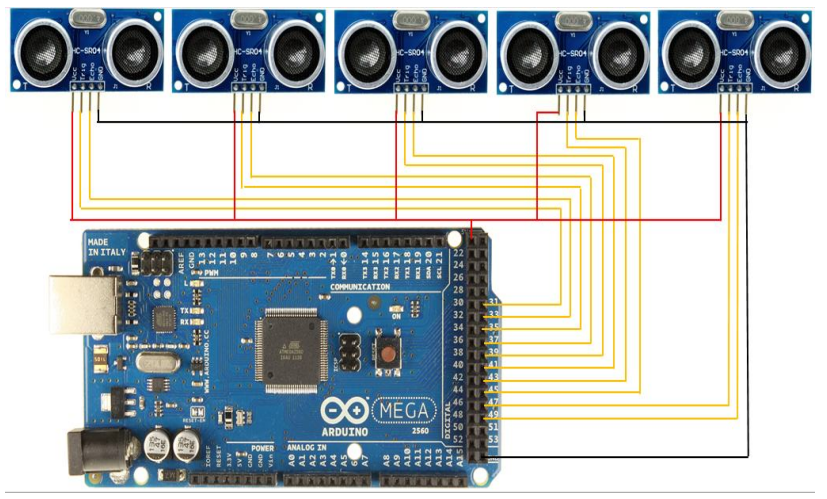

Gambar 6. Koneksi antara sensor ultrasonik dengan mikrokontroler

Sensor lainnya yang digunakan dalam robot adalah sensor api bertipe flame 5 channel dan sensor garis menggunakan LDR. Diagram koneksi sensor api dengan mikrokontroler diberikan pada Gambar 7. Kaki-kaki mikrokontroler yang digunakan untuk mengolah data dari sensor api diberikan oleh pin 8 sampai 12. Sementara itu, koneksi antara sensor garis dan mikrokontroler diperlihatkan pada Gambar 8 dengan memanfaatkan pin 13 mikrokontroler.

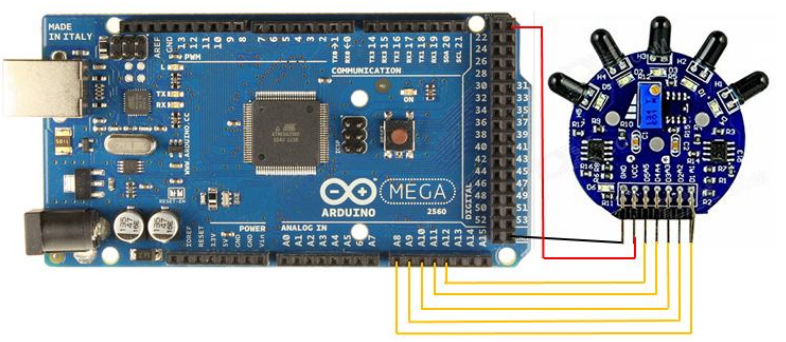

Gambar 7. Interkoneksi antara sensor api dengan mikrokontroler

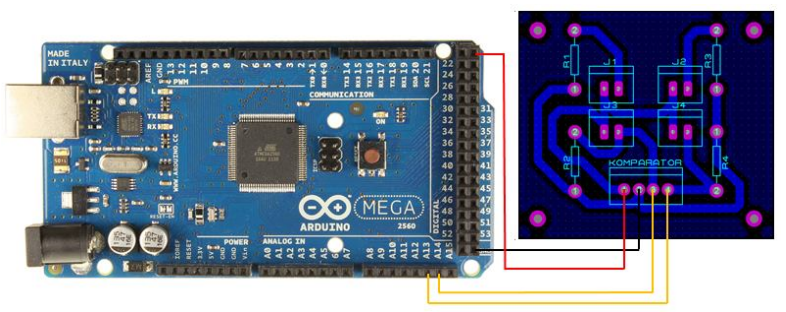

Gambar 8. Interkoneksi antara sensor garis dengan mikrokontroler

Mekanisme gerak robot heksapoda dihasilkan oleh struktur kaki yang terdiri atas tiga bagian utama yaitu coxa, femur, dan tibia. Coxa atau pinggul mempunyai fungsi untuk menahan berat tubuh pada posisi statis (misal berdiri) dan dinamis misalnya berjalan atau berlari). Beban terberat dirasakan oleh bagian ini. Femur atau tulang paha mempunyai fungsi sebagai penyambung antara coxa atau tulang pinggul dengan tibia atau tulang kering. Femur memberikan dukungan pada seluruh struktur rangka sehingga membantu dalam pergerakan kaki. Tibia atau tulang kering mempunyati fungsi membentuk engsel bersama dengan tulang paha yang disebut dengan lutut sehingga memungkinkan robot untuk berjalan, berlari dan menaiki tangga. Struktur kaki robot diberikan pada Gambar 9.

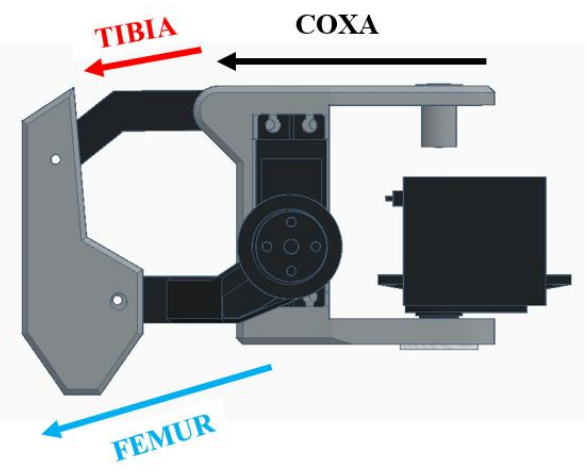

Gambar 9. Struktur kaki robot

Metode pergerakan kaki robot heksapoda mengikuti pola pergerakan tripod gait. Tripod gait terdiri dari kaki depan dan belakang serta kaki tengah pada sisi lainnya. Untuk setiap tripod, kaki diangkat, diturunkan, dan digerakkan maju mundur secara bersamaan. Pada saat berjalan, robot heksapoda menggunakan kedua tripodnya mirip dengan biped yang melangkah dari satu kaki ke kaki lain. Karena tiga kaki selalu berada di tanah, maka pergerakan tersebut akan selalu mantap. Dengan metode ini, sebuah siklus dapat diselesaikan dalam dua langkah sehingga memungkinkan robot dapat bergerak cepat. Skema pergerakan tripod gait diberikan pada Gambar 10.

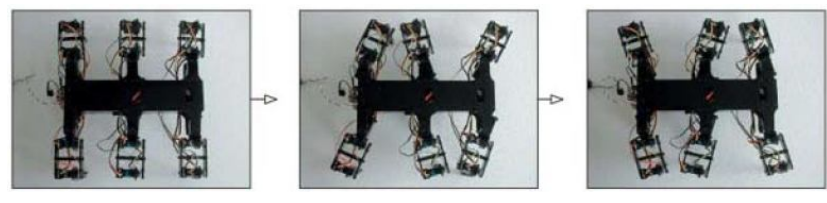

Gambar 10. Skema gerak tripod gait pada robot heksapoda

Setiap kaki digerakkan oleh dua motor servo. Untuk menghasilkan gerak, seluruh motor servo dikendalikan oleh modul penggerak bertipe XISC-32 servomotor controller. Koneksi antara modul penggerak motor servo dengan mikrokontroler diperlihatkan pada Gambar 11.

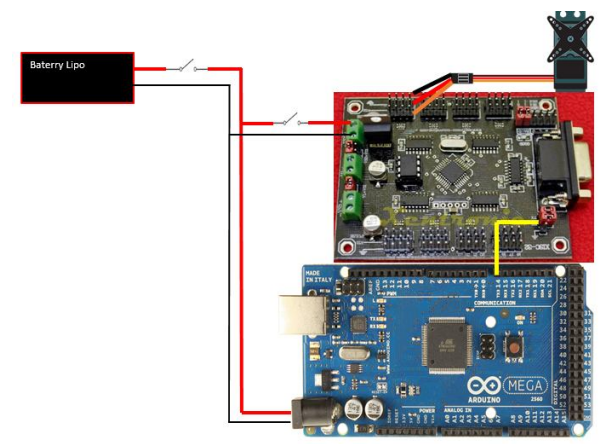

Gambar 11. Koneksi modul penggerak motor servo dengan mikrokontroler 


\section{HASIL DAN DISKUSI}

Integrasi setiap komponen menjadi satu kesatuan menghasilkan bentuk robot heksapoda yang direalisasikan dalam penelitian ini. Bentuk mekanik robot heksapoda yang direalisasikan diberikan pada Gambar 12. Sementara itu, bentuk fisik robot heksapoda diperlihatkan pada Gambar 14. Dimensi robot berukuran $25 \mathrm{~cm}$ x $21 \mathrm{~cm}$ x $27 \mathrm{~cm}$. Dalam Gambar 13 terlihat lima sensor ultrasonik terpasang di bagian depan robot beserta sensor dan kipas untuk memadamkan sumber api.

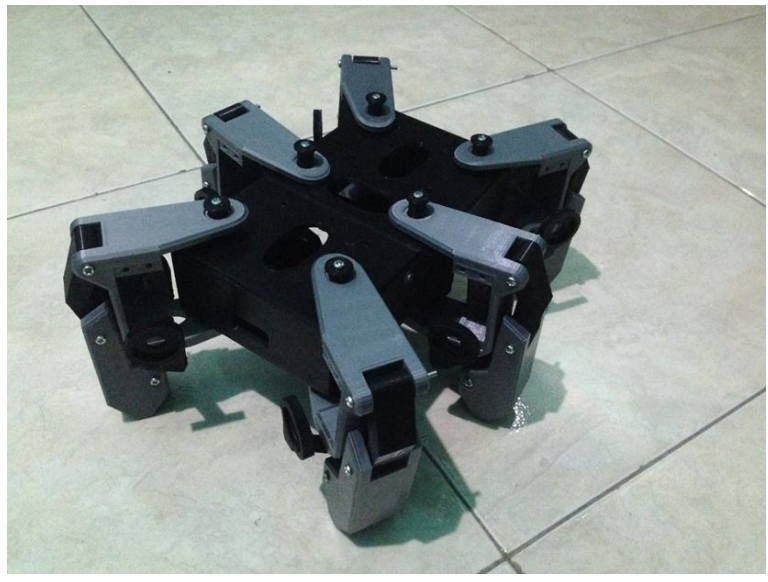

Gambar 12. Bentuk mekanik robot heksapoda

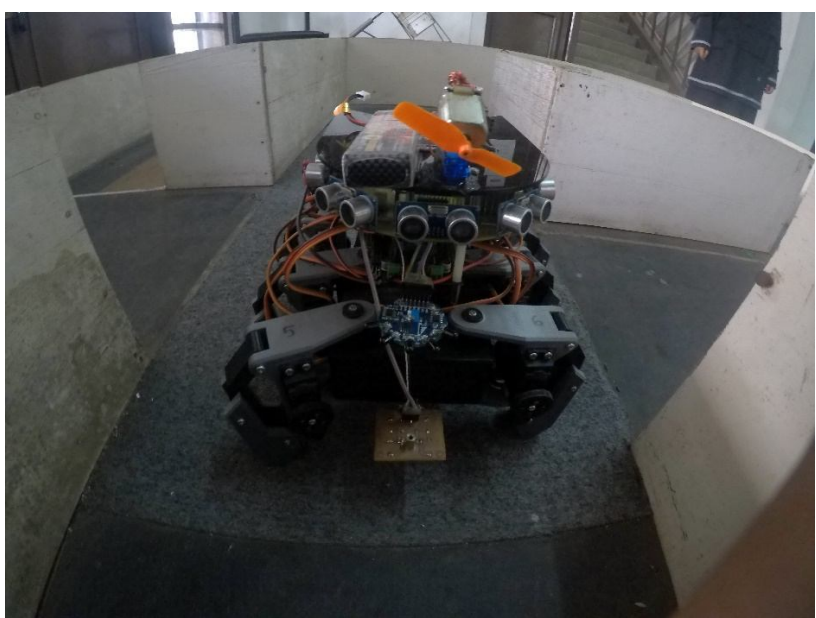

Gambar 13. Realisasi robot heksapoda

Selama pengujian, pergerakan robot mengikuti diagram alir yang diberikan pada Gambar 14. Pada saat robot mulai dijalankan, robot akan berada dalam posisi center dan menginisialisasi sensor lalu bernavigasi sehingga memasuki ruangan. Saat masuk ke dalam suatu ruang, robot akan menjejak (scan) apakah di dalam ruangan tersebut ada sumber api atau tidak. Jika sensor api tidak mendeteksi adanya sumber api dalam ruang, maka robot akan bergerak menuju ruangan lain. Jika dalam suatu fase gerak ditemukan adanya sumber api maka robot akan melanjutkan navigasi ke dalam ruangan tersebut untuk mendekati api dan memadamkannya dengan menggunakan kipas.

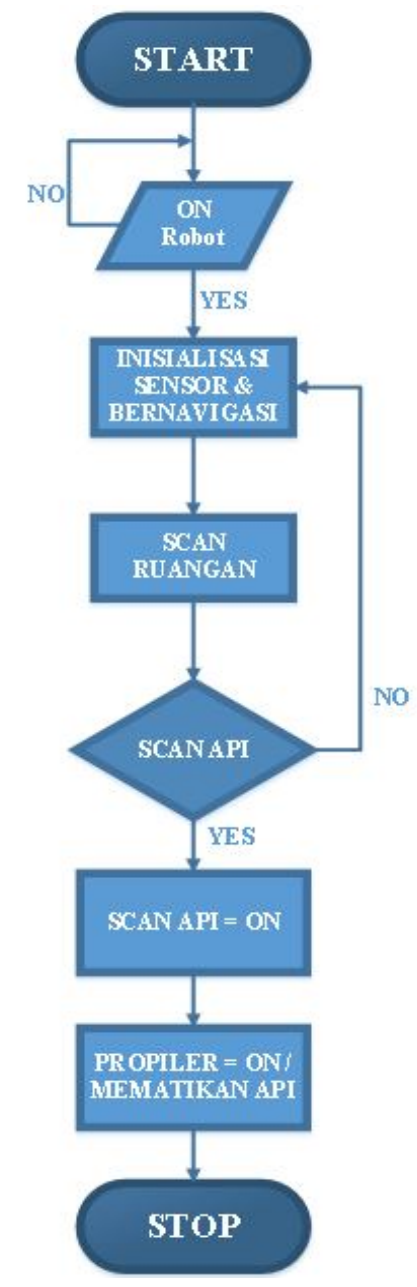

Gambar 14. Diagram alir pergerakan robot

Snapshot hasil pengujian diberikan pada Gambar 15 . Gambar 15 sebelah kanan memperlihatkan saat robot bergerak menyusuri ruangan berdinding dan bernavigasi mencari sumber api, sedangkan gambar sebelah kiri memperlihatkan robot memasuki ruang tempat sumber api berada.

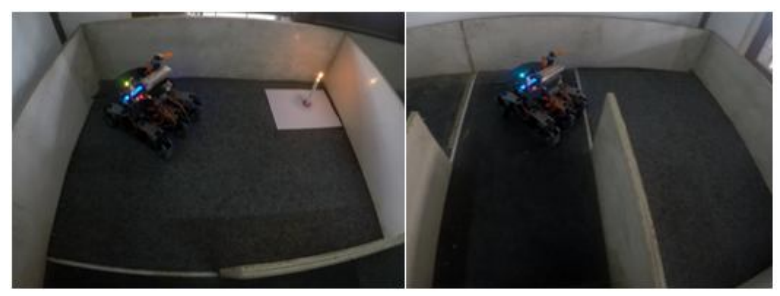

Gambar 15. Snapshot pergerakan robot dalam ruang

Saat robot menemukan sumber api, robot bergerak dalam ruang tersebut sampai sensor garis menemukan area berwarna putih. Ketika area putih terdeteksi, robot berhenti dan pengendali mengirimkan sinyal penggerak untuk memutar 
kipas sampai api padam. Hasil pengujian saat ditemukan sumber api dan kipas berputar untuk memadamkan api diberikan pada Gambar 16.

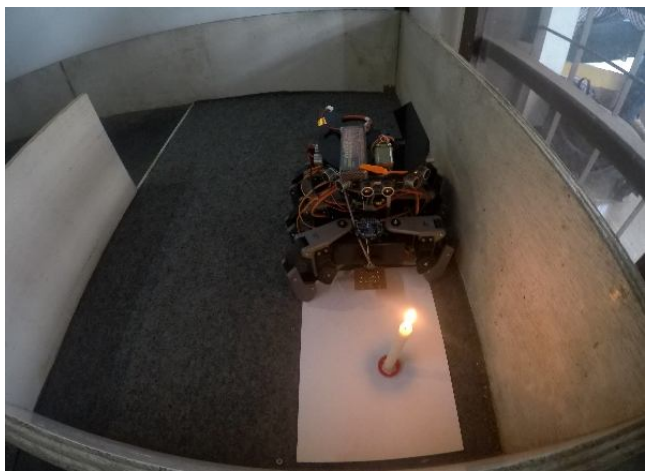

Gambar 16. Robot menemukan sumber api dan memadamkannya dengan kipas yang berputar

Dalam penelitian ini, ukuran performansi robot ditentukan dari kemampuan menghindari halangan dan tabrakan dengan dinding serta navigasi ke arah sumber api dan memadamkannya. Secara kuantitatif, jarak antara robot dengan dinding dijaga tidak kurang dari $10 \mathrm{~cm}$ sehingga robot tidak menabrak dinding. Waktu yang diperlukan saat sensor garis menemukan ruang tempat sumber api berada dan saat kipas mulai berputar diperoleh tidak lebih dari satu detik, sehingga respon dari driver motor pemutar kipas relatif cepat.

\section{KESIMPULAN}

Dalam makalah ini, desain dan implementasi robot heksapoda dengan misi pemadam api telah diuraikan dengan lengkap. Dengan perangkat sensor ultrasonik, robot dapat berjalan efektif menyusuri ruang tanpa menabrak dinding pemisah karena informasi jarak antara dinding dan robot selalu diperoleh setiap saat. Gerak langkah robot dapat direalisasikan dengan baik menggunakan modul pengendali servo motor yang terpasang di setiap kaki robot. Navigasi robot sampai menemukan sumber api dan memadamkannya tercapai dengan bantuan sensor garis dan sensor api yang terinstalasi dalam robot tersebut. Eksplorasi teknik kendali seperti PID atau teknik kendali cerdas seperti logika fuzzy dalam robot merupakan hal-hal penting yang dapat dilakukan dalam penelitian selanjutnya untuk menjamin ketercapaian performansi yang ditambahkan dalam sistem seperti kriteria respon waktu atau kekokohan robot terhadap gangguan yang muncul. Penggunaan pemroses citra yang telah diterapkan pada robosoccer seperti yang dilaporkan dalam [12] juga dapat dieksplorasi penerapannya dalam robot heksapoda untuk menghasilkan navigasi yang baik karena citra sekeliling robot dapat dikenali baik dimensi maupun warnanya.

\section{UCAPAN TERIMAKASIH}

Ucapan terima kasih disampaikan kepada para mahasiswa yang tergabung dalam kelompok riset robotik di Jurusan Teknik Elektro yang telah membantu dalam menguji dan mengimplementasikan hasil perancangan robot heksapoda yang diuraikan dalam makalah ini. Penelitian ini sebagian didanai melalui penelitian kompetitif Unjani tahun anggaran 2016. Oleh karena itu, ucapan terima kasih juga disampaikan kepada LPPM Unjani yang telah membantu sehingga penelitian ini dapat terlaksana dengan baik.

\section{DAFTAR PUSTAKA}

[1] X. Ding and F. Yang, "Study on hexapod robot manipulation using legs", Robotica Journal, Volume 34, Issue 2 February 2016 , pp. 468 481.

[2] A. Spröwitz, A. Tuleu, M. Vespignani, M. Ajallooeian, E. Badri, A. J. Ijspeert, "Towards dynamic trot gait locomotion: Design, control, and experiments with Cheetah-cub, a compliant quadruped robot", The International Journal of Robotics Research, Vol. 32 No. 8 (2013), pp. 932-950.

[3] X. Chai, F. Gao, C.K. Qi, Y. Pan, Y.L. Xu, and Y. Zhao, "Obstacle avoidance for a hexapod robot in unknown environment", Science China Technological Sciences June 2017, Vol. 60, No. 6, pp 818-831.

[4] W. S. Yu \& C. W. Huang, "Visual servo control of the hexapod robot with obstacle avoidance", IEEE International Conference on Fuzzy Systems, Beijing, 6-11 July 2014, pp. 713-720.

[5] G. Zhong, H. Deng, G. Xin, and H. Wang, "Dynamic Hybrid Control of a Hexapod Walking Robot: Experimental Verification", IEEE Transactions on Industrial Electronics, Vol. 63, No. 8, Aug. 2016, pp. 5001-5011.

[6] X. Zhao, Y. Pan and F. Gao, "Force-Position Hybrid Control of a New Parallel Hexapod Robot for Drilling Holes on Fuselage Surface", Proceedings of the ASME 2013 International Design Engineering Technical Conferences and Computers and Information in Engineering Conferenc, Portland, Oregon, USA, August 4-7, 2013, Vol. 6B, pp. 111.

[7] P. P. Wang, L. Liu, and Q. R. Qian., "Dynamic Modeling and Control of Flexible Hexapod Platform for Micro-Vibration Isolation and Precision Tracking", Applied Mechanics and Materials, Vols. 490-491 (2014), pp. 412-420.

[8] W. Li, S. Yuan, H. Huang, "Adaptive fuzzy vibration control of large flexible truss with Hexapod active interface”, Intern. Conf. on Systems and Informatics, Yantai, China, 19-20 May 2012, pp. 351-356.

[9] T. Fischer, T. Pire; P. Čížek, P. D. Cristóforis, and J. Faigl, "Stereo vision-based localization for hexapod walking robots operating in rough terrains", International Conference on Intelligent Robots and Systems (IROS), Daejeon, South Korea, 9-14 Oct. 2016, pp. 2492-2497.

[10] Anonim, Petunjuk Pelaksanaan Kontes Robot Indonesia, Ditjen Belmawa Kemenristekdikti, 2017.

[11] A. Najmurrokhman, Kusnandar, B. Wibowo, dan A. M. Annas, "Perancangan Instrumen Pengukur Ketinggian Menggunakan Sensor ADXL345 Yang Terkoneksi Dengan Smartphone Berbasis Android", Seminar Material, Instrumentasi, Pembelajaran, Dan Aplikasinya, Bandung, 5 November 2016.

[12] A. Najmurrokhman, Kusnandar, B. Wibowo, dan S. Abiddin, "Desain dan Realisasi Pemrosesan Citra dengan CMUcam4 untuk Meningkatkan Kinerja Visual Robosoccer," Prosiding Modern Electrical Engineering Technology and Its Application Seminar (MEETAS), Bandung, 28 Oktober 2016. 